\title{
EZEQUIEL DE OLASO: UN HOMBRE LIBRE*
}

MARIO PRESAS

Casi treinta años, casi la mitad de mi vida se entreteje en un trato ininterrumpido y fecundo con Ezequiel. Acerca de ello no puedo hablar, porque sería como hablar de mí. Voy a hacerlo más desde afuera, en nombre de la institución que Ezequiel creó con algunos amigos, en 1965: el Centro de Investigaciones Filosóficas (CIF). Fue cuando contó sus experiencias en el campo de la filosofía, en un ciclo de charlas sobre "La Argentina actual, por sí misma" organizado por Lucia Piossek de Zucchi en la Universidad de Tucumán, hacia finales de la década de $1970,{ }^{1}$ en lugar de referirse a sus importantes publicaciones y a sus múltiples tareas de investigación y docencia, prefirió nombrar unas cuantas actividades que tenian en común una finalidad: establecer instituciones duraderas y fecundas. Entre estas actividades destaca en primer lugar la creación del Centro de Investigaciones Filosóficas y de la Revista Latinoamericana de Filosofía (RLF). Luego reseñó su doctorado en Estados Unidos y finalmente, habló de que, junto con su amigo Porchat Pereira —como contaba también Marcelo Dascal—organizó un centro de investigación en la Universidad de Campinas, Brasil. Tanto el CIF como la $R L F$ han sobrevivido a las difíciles circunstancias económicas y políticas de las últimas décadas no por milagro, sino por el espíritu de diálogo y cooperación que los anima, y que alentaba radicalmente el espíritu de Olaso. Dichas instituciones estuvieron y siguen estando abiertas a

* Ezequiel de Olaso falleció el 27 de mayo de 1996. Marta, Miguel, Juan y Manuel de Olaso, junto con el Centro de Investigaciones Filosóficas (CIF), La fundación Ortega y Gasset Argentina, la Universidad de Buenos Aires y la Universidad de San Andrés, convocaron a un homenaje en el Centro Cultural Borges, en Buenos Aires, el 30 de julio de 1996, en el cual leí estas palabras. Unas semanas más tarde, el 28 de agosto de 1996, mi colega y amigo Oscar Nudler, en su carácter de Coordinador General del III Coloquio Internacional Bariloche de Filosofía, me solicitó que participara, como presidente del CIF, en otro acto en el cual volvi a leer, con algunas variantes, mi emocionado homenaje al gran amigo y brillante filosofo Ezequiel de Olaso.

1 Autopresentación, Ciclo: "La Argentina actual, por sí misma", Universidad Nacional de Tucumán, 1980. 
todas las corrientes, ideas y tendencias filosóficas, con la única condición de que los conceptos se elaboren con rigor y se expresen mediante una argumentación racional, esto es, que se apele a la razón como última instancia universalmente válida.

Sobre su doctorado en el Bryn Mawr College, en Pensilvania, bajo la dirección de José Ferrater Mora, diré sólo algo, que lo pinta de cuerpo entero y que sigue siendo un buen ejemplo para los discípulos: no eligió un tema fácil; por el contrario, buscó un problema sumamente acotado y de enormes dificultades: escribir un comentario literal a una obra de Leibniz contra Descartes. (Esto fue más arduo aún y más excitante cuando pudo demostrarle a un reconocido scholar como era Popkin, que un escrito de Leibniz sobre Sexto Empírico que se creía perdido era uno que el propio Ezequiel había descubierto en el archivo de Hannover.) ¿Por qué se impuso un trabajo tan exigente? Porque -como él mismo dice de Borges- "amaba las aventuras del pensamiento; cosa rara entre los intelectuales". ${ }^{2}$ Así se veía obligado a estudiar la filosofía moderna con los mismos recaudos que se emplean para estudiar la filosofía antigua, de modo que, confiesa, "con el pretexto de comentar un escrito de veinte páginas, tenía que ejercitarme en la historia entera de la filosofía [...] Esa escuela, ese taller, fue muy productivo, y siempre que puedo les recomiendo a mis alumnos y flamantes colegas que se inventen una tarea similar". ${ }^{3}$

$\mathrm{Si}$, aparte de sus logros científicos, tuviera que señalar el rasgo más importante de Ezequiel de Olaso, diría que fue un hombre libre y ecuánime; el hombre más libre que me fue dado conocer. Y sobre esa distendida manera de ser afloraban una inusual generosidad, un humor y una ironía incomparables. Acaso lo que más aborrecía eran la intolerancia y la soberbia de los fundamentalistas, la "canallada institucional" que silencia la abjuración de Galileo ante el tribunal de la Inquisición. ${ }^{4}$ No le agradaba la ligereza con que, entre nosotros, se daba la bienvenida a una posmodernidad trasplantada de otros pueblos que, justamente, habían hecho la experiencia del liberalismo democrático. Consideraba que nuestros países latinoamericanos aún no habían pasado por esa prueba. De ahí que no sea anecdótica su pública refutación del frívolo profetismo de Baudrillard, ni incidental su interés en la obra de uno de los pocos espíritus ilustrados de la España del siglo xviI, el sacerdote Benito Jerónimo Feijoo, y en el eco que tuvo en Domingo Faustino Sarmiento; veía en ellos una clave de nuestra situación en el mundo occidental. Citaba a Sarmiento, quien decía: "Feijoo es el primer español que empieza a difundir ideas nuevas sobre asuntos que no sean saber si

2 E. de O., "Borges, la poesía del pensamiento", La Nación, 29 de marzo de 1987.

3 Autopresentación.

4 E. de O., "Descartes: el creador de la modernidad", La Nación, 31 de marzo de 1996. 
Jesucristo era buen mozo, etc."; sino que denuncia que la educación que se daba en América consistía en "enseñar a ignorar científicamente la verdad verdadera de las cosas, y no la verdad deducida de textos y tradiciones". ${ }^{5}$

Esa verdad verdadera de las cosas se logra con el cultivo desinteresado (quiero decir, no ideológico) de la filosofía, y repercute en una fundamentación de la sociedad en la comprensión mutua y en el diálogo, esto es, en la razón. A los apocalípticos posmodernos que se regodean con el epígrafe de un famoso grabado de Goya, "Los sueños de la razón también producen monstruos", Ezequiel les recordaba - hace apenas tres meses-6 que "las vigilias de la razón trajeron maravillas".

Compartía Ezequiel la "poesía del pensamiento" de Borges, quien imaginó el principio del filosofar ${ }^{7}$ en el diálogo de dos griegos desconocidos que, por lo pronto, están de acuerdo en una sola cosa: "la discusión es el no imposible camino para llegar a una verdad [...] Libres del mito y de la metáfora, piensan o tratan de pensar [...] Han olvidado la plegaria y la magia".

De las muchas páginas que Ezequiel dedicó a Borges, extraigo algunas líneas ${ }^{8}$ para aplicárselas a él mismo, en mi opinión, con justicia:

Ha terminado para él la tensión agnóstica que nos trabaja a muchos. Ahora sabe o ni siquiera ignora. Imagino que el buen Dios le ha ofrecido el paraíso, la eternidad del puro deleite contemplativo, un Aleph interminable. De un modo que las palabras no pueden transmitir, está viendo sonriente que padeció una ilusión de porteño o incorregible y que los hombres burlan otra vez los frágiles ardides de la literatura [y de la filosofía].

5 E. de O., "El padre Feijoo y Domingo F Sarmiento", ECO, Bogotá, no. 176, 1975.

6 La Nación, 28 de abril de 1996.

7 J.L. Borges, "El principio", Obras completas, Emecé, Buenos Aires, 199l, t. III, p. 175.

8 E. de O., "Borges, la poesía del pensamiento". 